\title{
Kinetic Analysis of Xylose Production from Palm Pressed Fiber by Sulfuric Acid
}

\author{
Wiboon Riansa-ngawong* \\ Department of Agro-Industry Technology and Management, Faculty of Agro-Industry, King Mongkut's University \\ of Technology North Bangkok, Prachinburi Campus, Prachinburi, Thailand
}

\author{
Maneewan Suwansaard \\ Department of Biological Sciences, Bowling Green State University, Bowling Green, Ohio, USA
}

\begin{abstract}
Poonsuk Prasertsan
Department of Industrial Biotechnology, Palm Oil Products and Technology Research Center (POPTEC), Faculty of Agro-Industry, Prince of Songkla University, Songkhla, Thailand

The Joint Graduate School of Energy and Environment (JGSEE), King Mongkut's University of Technology Thonburi, Bangkok, Thailand

* Corresponding author. E-mail: wiboon.007@gmail.com

Received: 8 October 2014; Accepted: 1 December 2014; Published online: 2 February 2015

(C) 2015 King Mongkut's University of Technology North Bangkok. All Rights Reserved.
\end{abstract}

\begin{abstract}
Palm pressed fiber (PPF) is lignocellulosic materials containing xylose and glucose. These high sugars contained in PPF can be used as a substrate for ethanol production by microorganisms. The PPF was delignified using sodium hypochlorite as a pretreatment for sugars production. By using mathematic model, $30.6 \mathrm{~g} \mathrm{~L}^{-1}$ of xylose and $2.2 \mathrm{~g} \mathrm{~L}^{-1}$ of glucose was obtained under the optimum condition of $5 \%\left(v \cdot v^{-1}\right) \mathrm{H}_{2} \mathrm{SO}_{4}$ at $120^{\circ} \mathrm{C}$ for $30 \mathrm{~min}$. At this condition, acetic acid and furfural concentrations were produced at $7.2 \mathrm{~g} \mathrm{~L}^{-1}$ and $0.9 \mathrm{~g} \mathrm{~L}^{-1}$, respectively. Kinetic parameters were also investigated in order to predict concentrations of xylose, glucose, acetic acid and furfural in the delignified PPF hydrolysate. Yield of xylose was $85.74 \%$ of the initial xylose content.
\end{abstract}

Keywords: Xylose production, Palm pressed fiber, Optimization, Dilute sulfuric acid

\section{Introduction}

Palm pressed fiber (PPF) is a renewable lignocellulosic material generated from palm oil production with the quantity of about $12 \%$ of fresh fruit bunches (FFB) in Thailand [1]. The PPF is produced at approximately 8.56 million ton/year [2]. They are commonly used as boiler's heat energy in oil palm industries. PPF composes of cellulose (\%), hemicellulose (\%), and lignin (\%) [3]. Main sugar components of hemicellulose are xylose and glucose [3]. An alternative PPF utilization is to produce value added chemical compounds such xylose, furfural, and acetic acid. Xylose is used as a sweetener in food industries [4] and ethanol production [5,6], furfural can be used as an important intermediate for production of fuel and chemicals [7] and acetic acid is always used as food additive (vinegar) and microbial inhibitor [8]. To breakdown PPF fiber into hemicellulose, verities of acid catalysts including sulfuric acid $[9,10]$, hydrochloric acid [11], hydrofluoric acid [12], acetic acid [13], phosphoric acid [14] or nitric acid [15] are used. Catalytic efficiency $(E)$ is a factor to compare each hydrolytic process. The catalytic efficiency is defined as the equation (1) below [15]:

Please cite this article as: W. Riansa-ngawong, M. Suwansaard, and P. Prasertsan, "Kinetic Analysis of Xylose Production from Palm Pressed Fiber by Sulfuric Acid," KMUTNB Int J Appl Sci Technol, Vol.8, No.1, pp. 65-75, Jan.-Mar. 2015, http://dx.doi.org/10.14416/j.ijast.2014.12.001 
$E=\frac{\Sigma S}{\Sigma I}$

where $\Sigma S$ is the sum of sugars concentrations in the hydrolysates and $\Sigma I$ is the sum of all inhibitors concentrations (acetic acid and furfural) in the hydrolysates. Sulfuric acid and nitric acid have been selected as it gives high value of $E$ (6.2 and 6.1, respectively) [15]. Sulfuric acid is preferable because it is more cost effective than nitric acid.

In acid hydrolysis, acetic acid is produced via autohydrolysis through hydronium-catalyzed reactions. The acetic acid brings the $\mathrm{pH}$ of the solution down to the range of 3-4. This lower $\mathrm{pH}$ leads to hydrolysis of xylose production from hemicellulose [9,10]. Moreover, furan such as furfural and hydroxymethyfurfural (HMF) which are inhibitory compounds in ethanol production can be produced through this process $[5,6]$. However, the reaction is not severe enough to hydrolyze the crystalline structure of cellulose and lignin. Therefore, cellulose and lignin remain as insoluble solid in the solution [9]. To maximize xylose and minimize other compounds production, the mathematic model was employed. There are several factors influencing on hydrolysis of lignocellulosic materials including size, particle shape, and structure of fibers. Acid type, acid concentration, and temperature and time of reaction need to be put into consideration as well.

Previously, Riansa-ngawong et al (2011) reported on xylose production from delignified PPF (DPPF), which is the PPF contains less lignin compounds in its structure. However, further maximizing xylose production need to be investigated as we aimed to use it as a substrate for ethanol production. Therefore, this work presents the kinetic model of xylose production and other compounds including glucose, furfural and acetic acid from dignified PPF using dilute sulfuric acid. The hydrolysis condition including sulfuric acid concentration, reaction temperature and reaction time were demonstrated to obtain more xylose, less inhibitory products.

\section{Materials and Methods}

\subsection{Preparation of delignified PPF}

Palm pressed fiber (PPF) was collected from Thai-Taro $\&$ Oil, Co., Ltd., Suratthanee Province, Thailand. The
PPF was sun-dried and ground to a particle size of $<0.5$ $\mathrm{mm}$ by sieve cut off ( 35 mesh analytical sieve, Fritsch, Germany). After oven-dried at $103^{\circ} \mathrm{C}$ overnight, the PPF powder was kept in a plastic bag and stored at room temperature $\left(30^{\circ} \mathrm{C}\right)$. Composition of PPF was analyzed according to the standard methods [16]. The process of delignification of PPF was previous described [17].

\subsection{Dilute sulfuric acid hydrolysis}

The DPPF was mixed with dilute sulfuric acid concentrations of $0 \%, 5 \%$ and $10 \% \mathrm{v} / \mathrm{v}$ in the ratio of $1: 10\left(\mathrm{w} \mathrm{w}^{-1}\right)[9,11,18,19]$. Operating temperatures of hydrolysis were varied between 75 and $148^{\circ} \mathrm{C}$ and $5 \mathrm{ml}$ of samples were taken at various time intervals in the range of 30-180 min. After reaction, solids were separated from aqueous solution by filtration. The filtrate was analyzed for xylose and glucose by using High Performance Liquid Chromatograph (HPLC), furfural and acetic acid by using GC-FID.

\subsection{Analytical assays}

Glucose and xylose were determined by HPLC (Hewlett-Packard, Agilent 1100, USA) with Zorbax $\mathrm{NH}_{2}$ column $(4.6 \times 250 \mathrm{~mm}, 5$-Micron, Agilent, USA) combined with a RI detector [20]. Mobile phase was acetonitrile and water in the ratio of $75: 25 \mathrm{v} \mathrm{v}^{-1}$ [9]. Operating temperatures was controlled at $25^{\circ} \mathrm{C}$. Flow rate was set at $1.0 \mathrm{ml} / \mathrm{min}$. Standard sugars were run in the same condition.

Furfural and acetate were analyzed by GC-FID (HP 6850, Hewlett Packard) using Stabilwax-DA column [17,21,22]. Flow rate for helium was $1.2 \mathrm{ml} \mathrm{min}{ }^{-1}$. The temperatures of injection port and detection port were $200^{\circ} \mathrm{C}$ and $230^{\circ} \mathrm{C}$, respectively. Injection volume was $1 \mu \mathrm{l}$. The initial temperature of oven was $70^{\circ} \mathrm{C}$ for 2 min followed with a ramp of $20^{\circ} \mathrm{C}$. $\mathrm{min}^{-1}$ for $1 \mathrm{~min}$ and to final temperature of $180^{\circ} \mathrm{C}$ for $2 \mathrm{~min}$. Under these conditions acetate and furfural have the retention time of $6.3 \mathrm{~min}$ and $6.5 \mathrm{~min}$, respectively. All experiments were carried out in triplicate and data were expressed in average values. The experimental data were fitted to the proposed equations and non-linear regression analysis were calculated using Sigma Plot version 10 (System software, Germany). 


\subsection{Kinetic models}

The acid hydrolysis models for cellulose hydrolysis involves polymer glucan of cellulose is degraded to glucose and then subsequently converted to decomposition products [9]. The process is represented as equation (2):

glucan $\rightarrow$ glu $\cos e \rightarrow$ decomposition products

Hemicellulose can be hydrolyzed by acid and proposed to exhibit two different kinetic mechanisms. The first mechanism, xylan is first converted to xylooligosaccharide, which is then converted to xylose by acid hydrolysis and then directly xylose is subsequently decomposed to furfural. Another mechanism, xylan is converted to xylose without any intermediate formation of xylooligosaccharide and finally xylose is decomposed to furfural. The final results of both mechanisms are the same. The kinetic model for hemicellulose hydrolysis is represented by the following equation (3):

$x y l a n \rightarrow$ xylose $\rightarrow$ decomposition products

Therefore, it can be generalized as equation (4):

polymer $\stackrel{k_{1}}{\rightarrow}$ monomer $\stackrel{k_{2}}{\rightarrow}$ decomposition products

where $k_{1}$ is the rate of monomer production $\left(\mathrm{min}^{-1}\right)$ and $k_{2}$ is the rate of monomer decomposed $\left(\mathrm{min}^{-1}\right)$. Based on this reaction, model or saeman's model and solving differential equations, monomer concentration $(M)$ as a function of time $(t)$ can be represented by equation (5):

$M=\left[\frac{k_{1} P_{0}}{\left(k_{2}-k_{1}\right)}\right]\left(e^{-k_{1} t}-e^{-k_{2} t}\right)+M_{0} e^{-k_{2} t}$

where $P$ and $M$ represents concentration of polymer and monomer, respectively. The subscript 0 represents at time $t=0$. $P_{0}$ was $35.77 \mathrm{~g} \mathrm{~L}^{-1}$ calculating from equation 14 . Assuming $M_{0}$ to be nearly equal to 0 , equation 5 could be modified to equation 6 :

$M=\left[\frac{k_{1} P_{0}}{\left(k_{2}-k_{1}\right)}\right]\left(e^{-k_{1} t}-e^{-k_{2} t}\right)$
The kinetic model for cellulose hydrolysis involves pseudo-homogeneous irreversible first order reactions represented by equation (7):

glucan $\stackrel{k_{3}}{\rightarrow}$ glu $\cos e \stackrel{k_{4}}{\rightarrow}$ decomposition products

where $k_{3}$ is the rate of glucose production $\left(\mathrm{min}^{-1}\right)$ and $k_{4}$ is the rate of glucose decomposed $\left(\mathrm{min}^{-1}\right)$. Actually, the operating conditions in this investigation did not want decomposition products. Thus, equation (7) can be modified as equation (8):

glucan $\stackrel{k_{3}}{\rightarrow}$ glu $\cos e$

According to solving differential equations, concentration of glucose $(G)$ as a function of time can be represented as equation (9):

$G=G_{0}\left(1-e^{-k_{3} t}\right)$

where $G_{0}$ is the potential glucose concentration calculated by regression analysis.

In addition, the kinetic model of furfural generation from xylose degradation is shown in equation (10). Thus the model of furfural concentration $(F)$ as a function of time can be represented as equation (11):

xylose $\stackrel{k_{4}}{\rightarrow}$ furfural

$F=F_{0}\left(1-e^{-k_{4} t}\right)$

where $F_{0}$ is the potential furfural concentration calculated by regression analysis and $k_{4}$ is also the furfural production rate $\left(\mathrm{min}^{-1}\right)$.

Acetic acid is a decomposition product obtained by acetyl group's degradation from hemicelluloses [9]. The model for acetic acid generation can be represented as equation (12):

acetyl groups $\stackrel{k_{s}}{\rightarrow}$ acetic acid

Acetic acid concentration (A) in the hydrolysates as a function of time can be represented as equation (13):

$A=A_{0}\left(1-e^{-k_{5} t}\right)$ 
where $A_{0}$ is the potential acetic acid concentration calculated by regression analysis and $k_{5}$ is the acetic acid production rate $\left(\mathrm{min}^{-1}\right)$.

Equations (6), (9), (11) and (13) were applied to sulfuric acid hydrolysis of DPPF. Non-linear regression analyses were performed to obtain the kinetic parameters and constants. Coefficient of determination $\left(R^{2}\right)$ was calculated in order to observe the reliability of the models $[9,18]$.

\section{Results and Discussion}

The main components of DPPF were cellulose $42.36 \pm 1.07 \%$, hemicellulose $38.96 \pm 0.67 \%$, and lignin $8.21 \pm 0.37 \%$ [17]. The hemicellulose fraction of this material was mainly xylan $\left(80.8 \%, \mathrm{w} \mathrm{w}^{-1}\right)$ and could be calculated to xylose content of $31.48 \%$. If we assume that xylan is completely converted to xylose without formation of any decomposition products, then $P_{0}$ can be represented by equivalent amount of xylose by equation (14):

$P_{0}=\left(\frac{X_{P 0} \times 150 \times 10}{132 \times L S R}\right)=35.77 \mathrm{~g}$ xylose $/ l$

where $X_{P 0}$ is the initial xylan polymer presented in the DPPF on dry basis (31.48 g xylan/100g DPPF), $150 / 132$ is the stoichiometric factor [9] and LSR is liquid solid ratio (10 g liquid/g DPPF).

Determination of DPPF hydrolysate showed that the highest release of xylose from hemicellulose was $30.67 \mathrm{~g} \mathrm{~L}^{-1}$ under dilute sulfuric acid concentration of $5 \% \mathrm{v} / \mathrm{v}$ (Figure $1 \mathrm{~b}$ ) which gave $85.74 \%$ of potential concentration of xylose. Reaction temperature and reaction time of xylose production were also important parameters affecting on release of xylose (Figure 1). In no sulfuric acid at $75-148^{\circ} \mathrm{C}$ (Figure 1a), the maximum xylose production $(9.10 \mathrm{~g} / 1$ or $25.44 \%)$ required higher reaction temperature $\left(120-148^{\circ} \mathrm{C}\right)$ and reaction time (180 $\mathrm{min})$. Moreover, at $10 \%$ sulfuric acid condition gave the maximum xylose released of $23.54 \mathrm{~g} \mathrm{~L}^{-1}$ or $65.81 \%$. This was because higher acid concentration with higher temperature could degrade xylose to furfural resulting on the decrease of xylose concentration in the DPPF hydrolysate (Figure $1 \mathrm{~b}$ and $1 \mathrm{c}$ ) and increase of furfural formation to $1.0 \mathrm{~g} \mathrm{~L}^{-1}$ (Figure 3c).

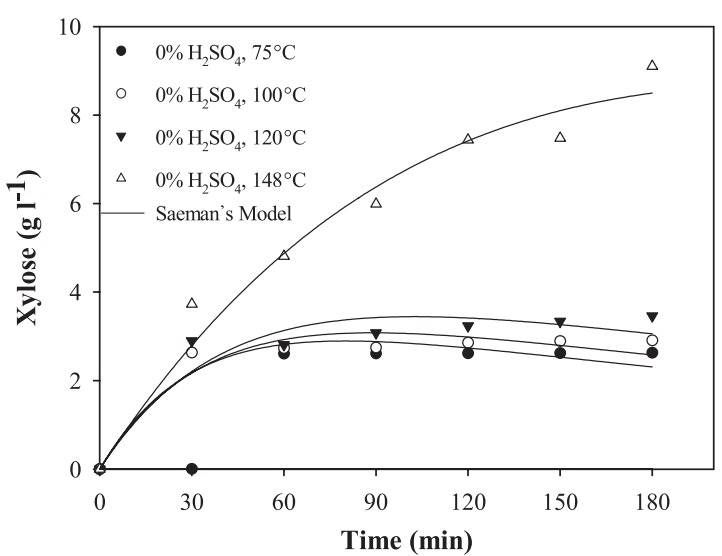

(a)

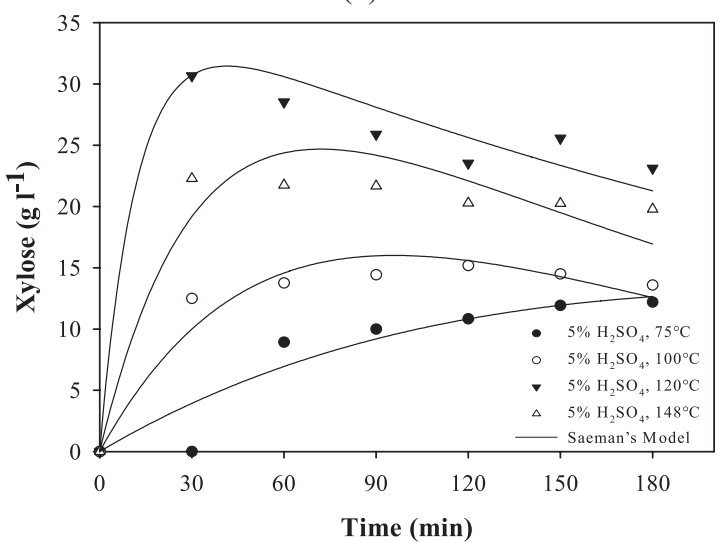

(b)

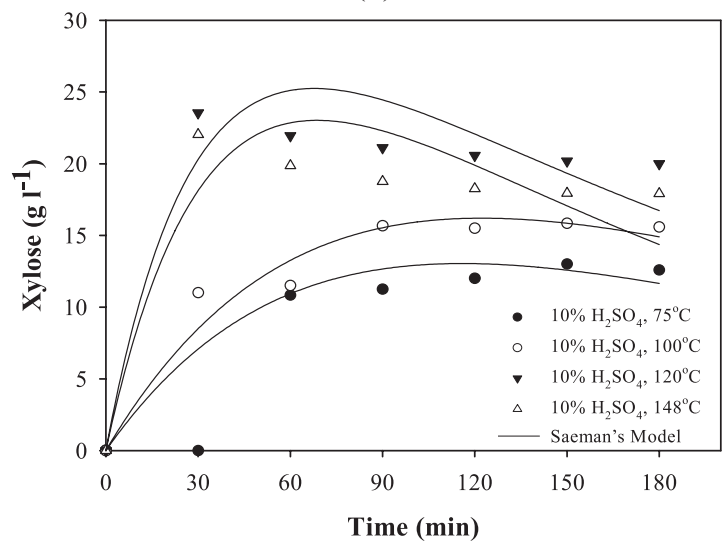

(c)

Figure 1: Experimental and predicted concentrations of xylose released from DPPF at: (a) autohydrolysis $(0 \%$ sulfuric acid) with various reaction temperature of $75-148^{\circ} \mathrm{C}$, (b) $5 \%$ sulfuric acid hydrolysis, and (c) $10 \%$ sulfuric acid hydrolysis with the same reaction temperature. 


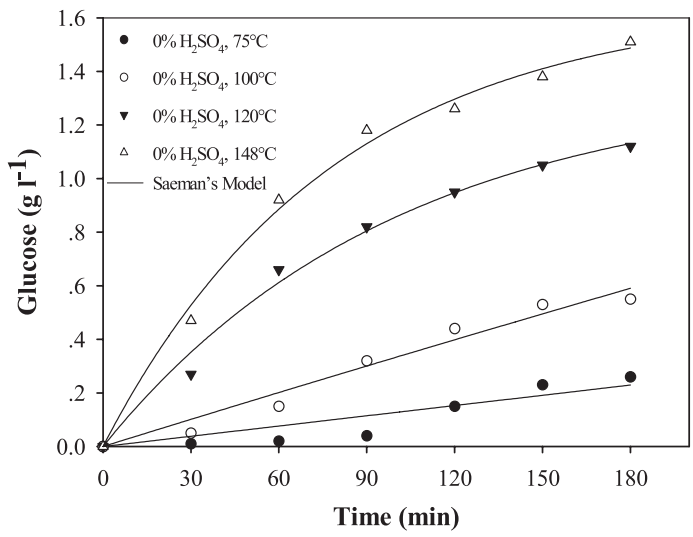

(a)

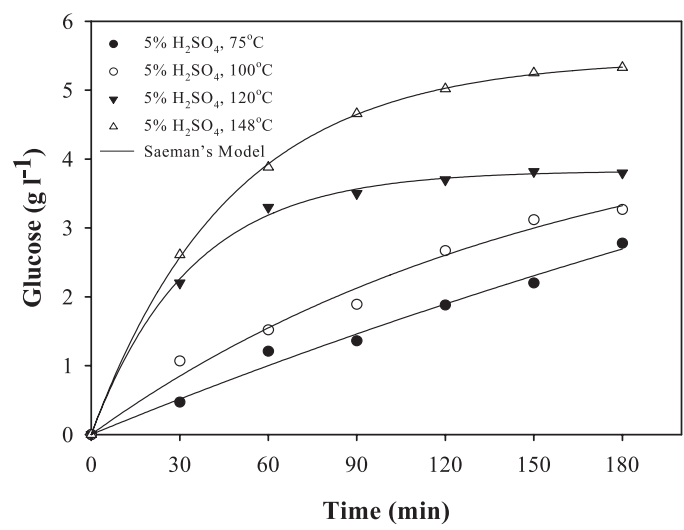

(b)

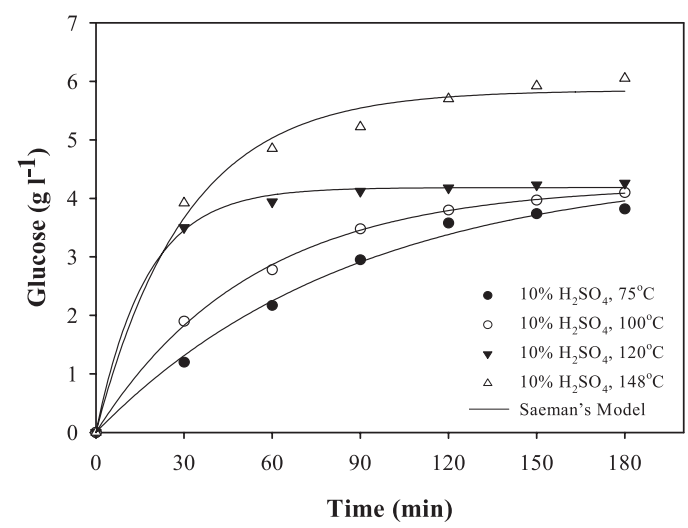

(c)

Figure 2: Experimental and predicted concentrations of glucose released from DPPF at: (a) autohydrolysis ( $0 \%$ sulfuric acid) with various reaction temperature of $75-148^{\circ} \mathrm{C}$, (b) $5 \%$ sulfuric acid hydrolysis, and (c) $10 \%$ sulfuric acid hydrolysis with the same reaction temperature.
Glucose was also released during acid hydrolysis of DPPF in lower concentration (Figure 2) with the maximum of $6.05 \mathrm{~g} \mathrm{~L}^{-1}$ under $10 \%$ sulfuric acid concentrations at $148^{\circ} \mathrm{C}$ for $180 \mathrm{~min}$ (Figure 2c). This was slightly higher than that at $5 \%$ sulfuric acid concentration $\left(5.33 \mathrm{~g} \mathrm{~L}^{-1}\right)$, and 4 times higher than that at $0 \%$ sulfuric acid concentration $\left(1.51 \mathrm{~g} \mathrm{~L}^{-1}\right)$. Normally, the release of glucose could be either from hemicellulose or cellulose chain [18]. However, the small glucose released in this study comes basically from hemicellulose by using dilute acid because dilute acid is not severe enough to hydrolyze the crystalline structure of cellulose $[9,18]$.

The amount of furfural formation as a decomposition product from xylose in the DPPF hydrolysate is shown in Figure 3. It was observed that there are some decomposition reactions leading to dehydration of xylose to furfural (Figure $3 b$ and 3c) [9]. The increase of sulfuric acid concentration and reaction temperature from 0 to $5 \%$ (Figure $3 \mathrm{a}$ and $3 \mathrm{~b}$ ) and 75 to $148^{\circ} \mathrm{C}$ (Figure 3a), respectively, resulted in the increase of furfural from 0.3 to $1.0 \mathrm{~g} / \mathrm{l}$. However, under the highest temperature at $148^{\circ} \mathrm{C}$ resulted in the decrease of furfural content (Figure 3c) because of furfural degradation to form formic acid by high temperature [6]. The highest concentration of furfural $\left(1.16 \mathrm{~g} \mathrm{~L}^{-1}\right)$ was generated using 5\% sulfuric acid and $60 \mathrm{~min}$ reaction time (Figure $3 b$ ). The maximum and minimum acetic acid generated in the DPPF hydrolysate were 8.02 and $0.65 \mathrm{~g} \mathrm{~L}^{-1}$ when sulfuric acid concentrations were 10 and $0 \%$, respectively, and reaction time of 90 and $30 \mathrm{~min}$, respectively (Figure 4).

\subsection{Kinetic model of xylose production}

Kinetic and statistical parameters obtained from DPPF hydrolysis at various reaction temperatures $\left(75-148^{\circ} \mathrm{C}\right)$ and sulfuric acid concentrations $(0-10 \%)$ are shown in Table 1. It was demonstrated that with both sulfuric acid concentrations $\left(5 \%\right.$ and $\left.10 \%, \mathrm{v} \mathrm{v}^{-1}\right)$ at reaction temperature $\geq 100^{\circ} \mathrm{C}$, xylose production rate $\left(k_{1}\right)\left(0.0102-0.0821 \mathrm{~min}^{-1}\right)$ was higher than the decomposition rate $\left(k_{2}\right)\left(0.0044-0.0510 \mathrm{~min}^{-1}\right)$. However, the $75^{\circ} \mathrm{C}$ reaction temperature had no effect on xylose production as the xylose production rate $\left(k_{1}\right)$ and the decomposition rate $\left(k_{2}\right)$ were nearly the same values $\left(0.0033-0.0031 \mathrm{~min}^{-1}, 0.0042 \mathrm{~min}^{-1}\right.$ and $0.085-0.0087 \mathrm{~min}^{-1}$ under $0 \%, 5 \%$ and $10 \%$ sulfuric 


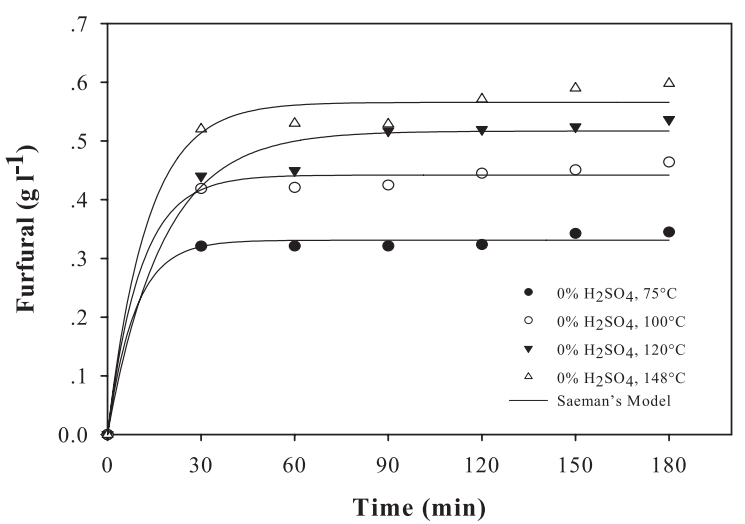

(a)

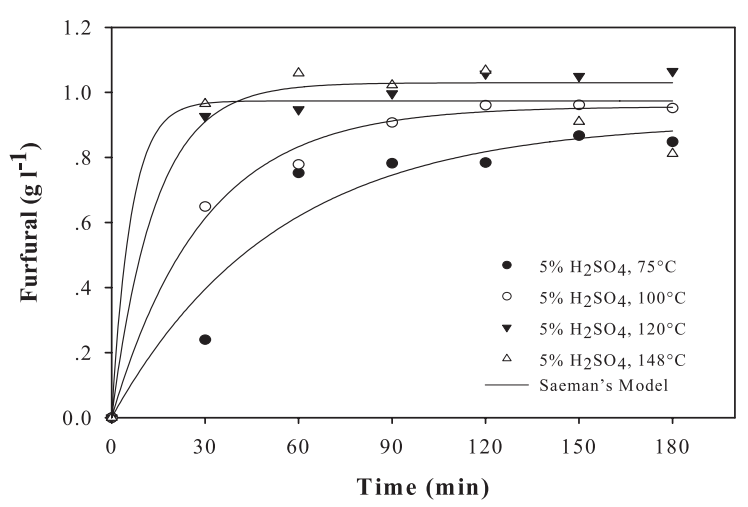

(b)

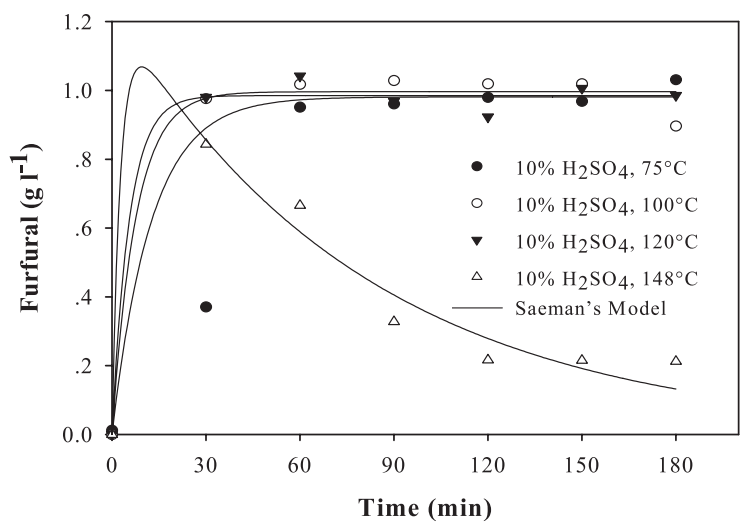

(c)

Figure 3: Experimental and predicted concentrations of furfural generated in DPPF hydrolysate at: (a) autohydrolysis ( $0 \%$ sulfuric acid) with various reaction temperature of $75-148^{\circ} \mathrm{C}$, (b) $5 \%$ sulfuric acid hydrolysis, and (c) $10 \%$ sulfuric acid hydrolysis with the same reaction temperature. acid, respectively). The determination of coefficient $R^{2}$ showed a good agreement between experimental and predicted data for all regressions. The increase in acid concentration resulted in the increase of $k_{1}$ and $k_{2}$ values. This indicated that to obtain maximum xylose with minimum furfural and acetic acid, an optimum reaction time was needed. For predicting all products, the modified model was developed by relating kinetic parameters with sulfuric acid concentration using empirical equation (equation 15) [9].

$k_{m}=k_{0} C_{a}^{n}$

where $m$ is in the range of 1 to $5 ; k_{0}$ and $n$ are the regression parameters; $C_{a}$ is sulfuric acid concentration expressed in $\%\left(\mathrm{~V} \mathrm{~V}^{-1}\right)$.

Therefore, generalized model for xylose production rate is represented by empirical equation (16) (Table 2) where $k_{1}$ is represented with acid concentration $\left(C_{a}\right)$. Similarly xylose degradation rate $\left(k_{2}\right)$ is represented by empirical equation (17). The determination coefficients $\left(R^{2}=0.92-0.98\right)$ for both parameters were in good agreement (Table 2). Combination of equations (16) and (17) with the model of xylose production and degradation, it is possible to predict xylose concentration within the time period (0-180 $\mathrm{min})$ and acid concentration $(0-10 \%)$ studied. The generalized model predicted that the maximum xylose concentration of $>30 \mathrm{~g} \mathrm{~L}^{-1}$ could be obtained with $5 \%$ sulfuric acid at $120^{\circ} \mathrm{C}$ for $30 \mathrm{~min}$. The dependence of xylose concentration with various acid concentrations and time period studied at $120^{\circ} \mathrm{C}$ were illustrated by response surface in Figure 5a. Therefore, reaction time of 30 min would be appropriated to obtain the maximum release of xylose $\left(30.67 \mathrm{~g} \mathrm{~L}^{-1}\right)$ with the minimum decomposition products $\left(7.1 \mathrm{~g} \mathrm{~L}^{-1}\right.$ acetic acid and $0.9 \mathrm{~g} \mathrm{~L}^{-1}$ furfural) in the DPPF hydrolysate.

\subsection{Kinetic model of glucose production}

Glucose is another product in hydrolysis of biomass, i.e. oil palm empty fruit bunch (OPEFB) [9], sorghum straw [18] and DPPF as well. In the model of glucose production (equation 9), the potential glucose concentration $\left(G_{0}\right)$ and kinetic parameter $k_{3}$ were obtained by regression and determination coefficient $\left(R^{2}=0.91-0.99\right)$ obtained was very high agreement with experimental (Figure 2, dot) and predicted data 


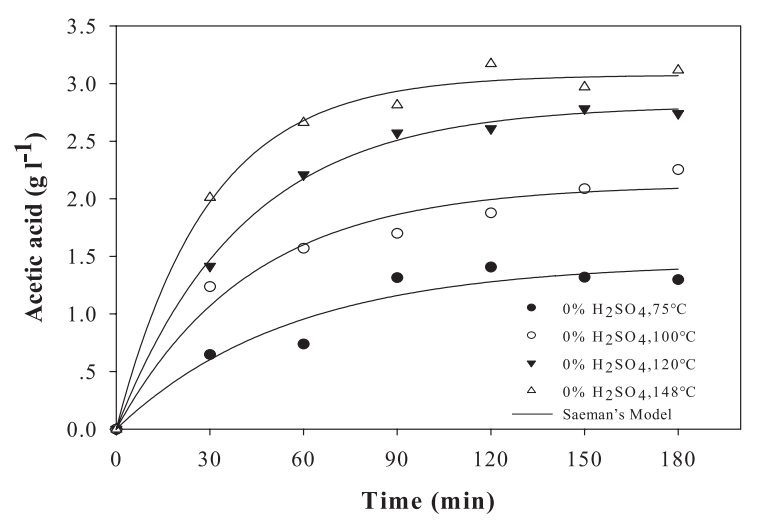

(a)

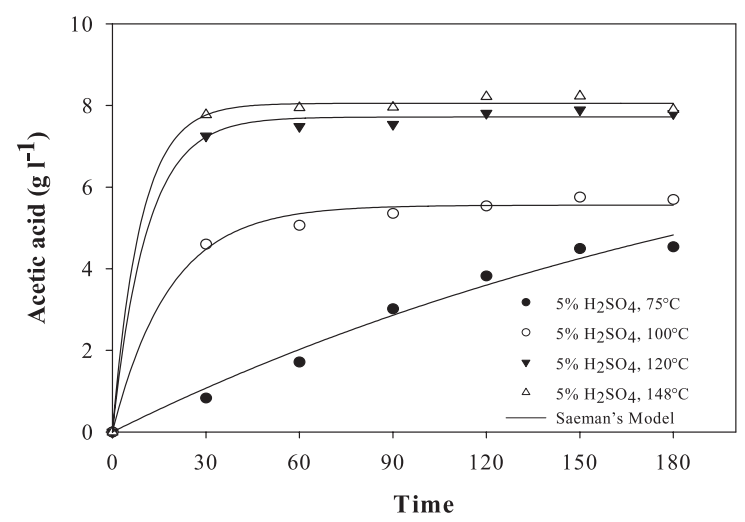

(b)

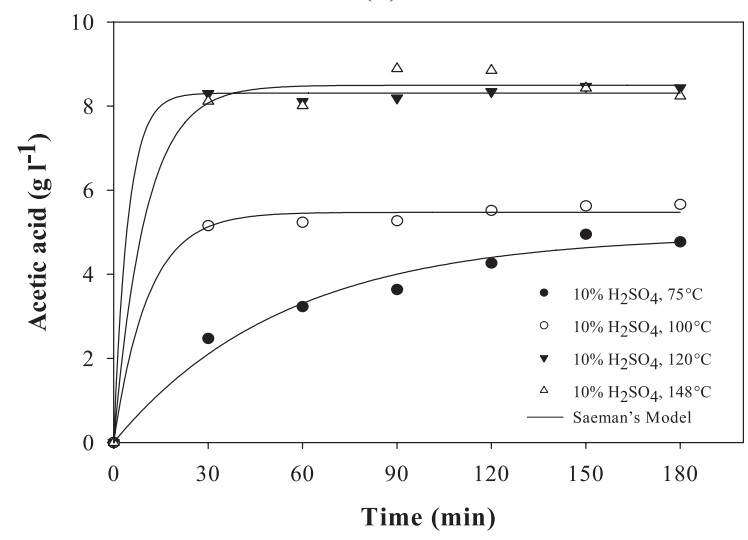

(c)

Figure 4: Experimental and predicted concentrations of acetic acid generated in DPPF hydrolysate at: (a) autohydrolysis $(0 \%$ sulfuric acid) with various reaction temperature of $75-148^{\circ} \mathrm{C}$, (b) $5 \%$ sulfuric acid hydrolysis, and (c) $10 \%$ sulfuric acid hydrolysis with the same reaction temperature.
(Figure 2, line). The values of $G_{0}$ obtained were in the range of $1.32-5.84$, corresponding to $3.12-13.79 \%$ of total cellulose in DPPF. The low glucose production of this study was the same value compared to glucose production from OPEFB $\left(2.34 \mathrm{~g} \mathrm{~L}^{-1}\right.$ or $4.43 \%$ of total glucan) [9] and sorghum straw (3.8 $\mathrm{g} \mathrm{L}^{-1}$ or $10.86 \%$ of total cellulose) [18]. The values of $k_{3}$ were in the range of 0.0004-0.0582 $\mathrm{min}^{-1}$ (Table 1) which increased with the increase in both acid concentration and reaction temperature. Therefore, the model for prediction of glucose production (equation 18) was developed correlated with acid concentration, reaction temperature and kinetic parameter $k_{3}$. In Table 1, it was observed that the values of $k_{3}$ (glucose production) was lower than $k_{1}$ (xylose production) because the amorphous structure of hemicellulose is easier to be hydrolyzed than crystalline structure of cellulose [9]. Experimental and predicted data of glucose production in the DPPF hydrolysate is given in Figure 2. Therefore, combination of equation (18) and glucose production model (equation 9) was feasible to predict the release of glucose within the experimental range studied. The highest glucose production predicted by the models was $5.84 \mathrm{~g} / 1$ using $10 \% \mathrm{v} \mathrm{v}^{-1}$ sulfuric acid concentration at $148^{\circ} \mathrm{C}$ for $180 \mathrm{~min}$. The $k_{3}$ presented by equation (18) with determinant coefficient $R^{2}$ were well fitted (Table 2). The response surface plot of the generalized model for glucose production with increase in acid concentration and reaction time is shown in Figure $4 \mathrm{~b}$. From the response surface plot, there was no decomposition reaction occurred during the hydrolysis process because the degradation of glucose to hydroxymethylfurfural (HMF) requires high temperature $\left(180-230^{\circ} \mathrm{C}\right)$ and pressure (1.5-2.0 $\left.\mathrm{MPa}\right)$ [23]. To obtain the maximum glucose concentration in this hydrolysate, it is necessary to keep the reaction temperature at $148^{\circ} \mathrm{C}$ with $10 \% \mathrm{v} \mathrm{v}^{-1}$ sulfuric acid concentration for $90 \mathrm{~min}$ as glucose concentration would not further increase significantly with longer reaction time (5.2-5.8 $\mathrm{g} \mathrm{L}^{-1}$ ) (Figure 2c). However, xylose production decreased from 30.67 to $19.84 \mathrm{~g} \mathrm{~L}^{-1}$. Therefore, the reaction have to do based on xylose production, which is the major reducing sugar obtained from DPPF material by using dilute acid hydrolysis.

\subsection{Kinetic model of furfural formation}

Furfural is the main degradation product of xylose in 
Table 1: Kinetics and statistical parameters of xylose, glucose, furfural and acetic acid released during dilute sulfuric acid hydrolysis of delignified palm pressed fiber (DPPF) at various reaction temperatures

\begin{tabular}{|c|c|c|c|c|c|c|c|c|c|c|c|c|}
\hline & \multicolumn{4}{|c|}{$0 \% \mathrm{H}_{2} \mathrm{SO}_{4}$} & \multicolumn{4}{|c|}{$5 \% \mathrm{H}_{2} \mathrm{SO}_{4}$} & \multicolumn{4}{|c|}{$10 \% \mathrm{H}_{2} \mathrm{SO}_{4}$} \\
\hline & $75^{\circ} \mathrm{C}$ & $100^{\circ} \mathrm{C}$ & $120^{\circ} \mathrm{C}$ & $148^{\circ} \mathrm{C}$ & $75^{\circ} \mathrm{C}$ & $100^{\circ} \mathrm{C}$ & $120^{\circ} \mathrm{C}$ & $148^{\circ} \mathrm{C}$ & $75^{\circ} \mathrm{C}$ & $100^{\circ} \mathrm{C}$ & $120^{\circ} \mathrm{C}$ & $148^{\circ} \mathrm{C}$ \\
\hline \multicolumn{13}{|l|}{ Xylose } \\
\hline$k_{l}\left(\min ^{-1}\right)$ & 0.0033 & 0.0031 & 0.0030 & 0.0030 & 0.0042 & 0.0128 & 0.0821 & 0.0293 & 0.0085 & 0.0102 & 0.0922 & 0.0277 \\
\hline$k_{2}\left(\min ^{-1}\right)$ & 0.0031 & 0.0276 & 0.0228 & 0.0063 & 0.0042 & 0.0044 & 0.0310 & 0.0052 & 0.0087 & 0.0065 & 0.0510 & 0.0064 \\
\hline$R^{2}$ & 0.96 & 0.96 & 0.95 & 0.98 & 0.94 & 0.97 & 0.98 & 0.95 & 0.96 & 0.97 & 0.94 & 0.92 \\
\hline \multicolumn{13}{|l|}{ Glucose } \\
\hline$k_{3}\left(\min ^{-1}\right)$ & 0.0051 & 0.0004 & 0.0100 & 0.0128 & 0.0019 & 0.0064 & 0.0297 & 0.0212 & 0.0114 & 0.0189 & 0.0582 & 0.0328 \\
\hline$G_{0}$ & 1.32 & 1.70 & 1.35 & 1.65 & 4.45 & 4.87 & 3.83 & 5.45 & 4.54 & 4.23 & 4.18 & 5.84 \\
\hline$R^{2}$ & 0.91 & 0.98 & 0.99 & 0.99 & 0.99 & 0.99 & 0.99 & 0.99 & 0.99 & 0.99 & 0.99 & 0.99 \\
\hline \multicolumn{13}{|l|}{ Furfural } \\
\hline$k_{4}\left(\min ^{-1}\right)$ & 0.1141 & 0.0954 & 0.0286 & 0.0794 & 0.0189 & 0.0341 & 0.0717 & 0.1612 & 0.0794 & 0.1312 & 0.1806 & 0.3706 \\
\hline$F_{0}$ & 0.33 & 0.44 & 0.52 & 0.57 & 0.91 & 0.96 & 1.03 & 0.97 & 0.98 & 0.99 & 0.98 & 0.01 \\
\hline$R^{2}$ & 0.99 & 0.99 & 0.99 & 0.99 & 0.97 & 0.99 & 0.99 & 0.97 & 0.99 & 0.99 & 0.99 & 0.98 \\
\hline \multicolumn{13}{|c|}{ Acetic acid } \\
\hline$k_{5}\left(\min ^{-1}\right)$ & 0.0180 & 0.0234 & 0.0247 & 0.0342 & 0.0041 & 0.0546 & 0.0918 & 0.1108 & 0.0185 & 0.0919 & 0.2213 & 0.0998 \\
\hline$A_{0}$ & 1.44 & 2.12 & 2.81 & 3.07 & 9.18 & 5.56 & 7.72 & 8.05 & 4.94 & 5.47 & 8.31 & 8.50 \\
\hline$R^{2}$ & 0.97 & 0.98 & 0.99 & 0.99 & 0.99 & 0.99 & 0.99 & 0.99 & 0.99 & 0.99 & 0.99 & 0.99 \\
\hline
\end{tabular}

Note: $k_{1}$ is xylose production rate $\left(\mathrm{min}^{-1}\right), k_{2}$ is xylose decomposition rate $\left(\mathrm{min}^{-1}\right), k_{3}$ is glucose production rate $\left(\mathrm{min}^{-1}\right), k_{4}$ is furfural production rate $\left(\mathrm{min}^{-1}\right), k_{5}$ is acetic acid generation rate $\left(\mathrm{min}^{-1}\right), G_{0}$ is the potential glucose concentration, $F_{0}$ is the potential furfural concentration, $A_{0}$ is the potential acetic acid concentration, and $R^{2}$ is regression coefficient.

the acid hydrolysis of DPPF. Kinetic and statistical parameters for furfural are given in Table 1. The potential furfural concentration $\left(F_{0}\right)$ and kinetic parameter $k_{4}$ were within the range of $0.01-1.03$ and 0.0286-0.3706 $\mathrm{min}^{-1}$, respectively. The determinant coefficients $\left(R^{2}=0.97-0.99\right)$ were very well fitted with furfural formation model. Experimental and predicted data (Figure 3) revealed that the $k_{4}$ value increased with the increase in both sulfuric acid concentration and reaction temperature. A generalized model of furfural production was modified to correlate $k_{4}$ with acid concentration and reaction temperature for prediction of furfural concentration at all acid concentrations, reaction temperatures and times within the operating ranges studied. The empirical equation (19) represents the generalized model (Table 2) with the response surface graph for furfural formation given in Figure 4c. From this graph, furfural production increased with the increase in acid concentration and reaction time. In fact, furfural is an inhibitory compound to fermentation process, therefore, its concentration must be minimized $\left(<0.5 \mathrm{~g} \mathrm{~L}^{-1}\right.$ for $>80 \%$ efficiency of ethanol production) to facilitate optimum use of DPPF hydrolysate for ethanol [5]. Results on response surface graphs of xylose (Figure 5a) and furfural (Figure 5c) production revealed that the hydrolysis process for the highest xylose production with the lowest furfural formation have to be conducted using higher acid concentration and lower reaction time. In this study, the optimum condition for the maximum xylose production (30.67 $\left.\mathrm{g} \mathrm{L}^{-1}\right)$ and the minimum furfural generation $\left(0.9 \mathrm{~g} \mathrm{~L}^{-1}\right)$ was $5 \%\left(\mathrm{v} \mathrm{v}^{-1}\right)$ sulfuric acid concentration at $120^{\circ} \mathrm{C}$ for $30 \mathrm{~min}$.

Table 2: Generalized models for kinetic parameters prediction of DPPF hydrolysis with dilute sulfuric acid at $120^{\circ} \mathrm{C}$

\begin{tabular}{|l|ll|c|}
\hline \multicolumn{1}{|c|}{ Products } & \multicolumn{2}{|c|}{ Models } & $\boldsymbol{R}^{\mathbf{2}}$ \\
\hline \multirow{2}{*}{ Xylose } & $k_{l}=0.063 C_{a}^{0.1660}$ & Eq. (16) & 0.99 \\
\cline { 2 - 4 } & $k_{l}=0.0092 C_{a}^{0.7370}$ & Eq. (17) & 0.99 \\
\hline \multirow{2}{*}{$\begin{array}{l}\text { Gucose } \\
\text { Acetic acid }\end{array}$} & $k_{l}=0.0065 C_{a}^{0.9511}$ & Eq. (18) & 0.99 \\
\cline { 2 - 4 } & $k_{I}=0.0173 C_{a}^{1.0011}$ & Eq. (19) & 0.95 \\
\cline { 2 - 4 } & $k_{l}=0.0214 C_{a}^{1.0017}$ & Eq. (20) & 0.98 \\
\hline
\end{tabular}

Note: $C_{a}$ is sulfuric acid concentration expressed in $\% \mathrm{v} / \mathrm{v}$

\subsection{Kinetic model of acetic acid production}

Acetic acid is the major product released from acetyl group degradation of hemicellulose in acid hydrolysis of DPPF. Kinetic and statistical parameters obtained 


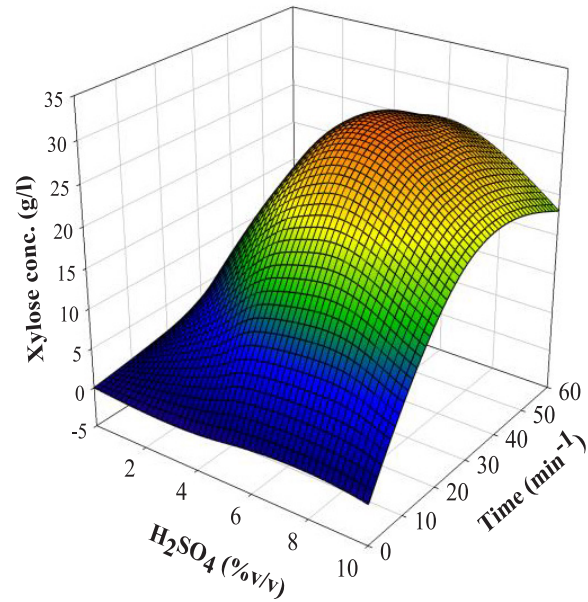

(a)

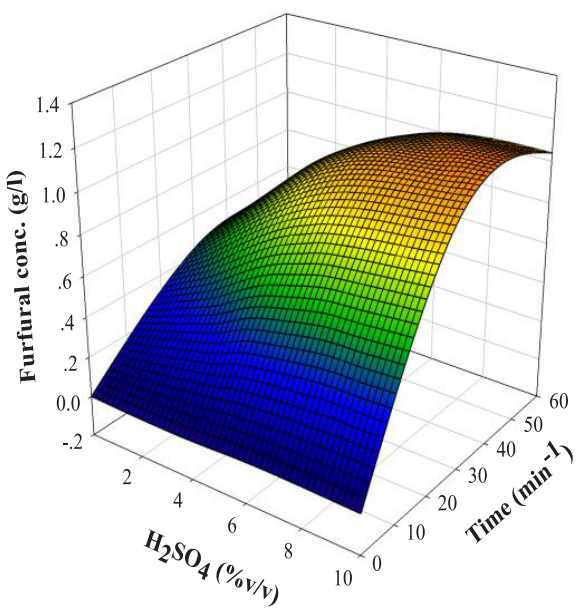

(c)

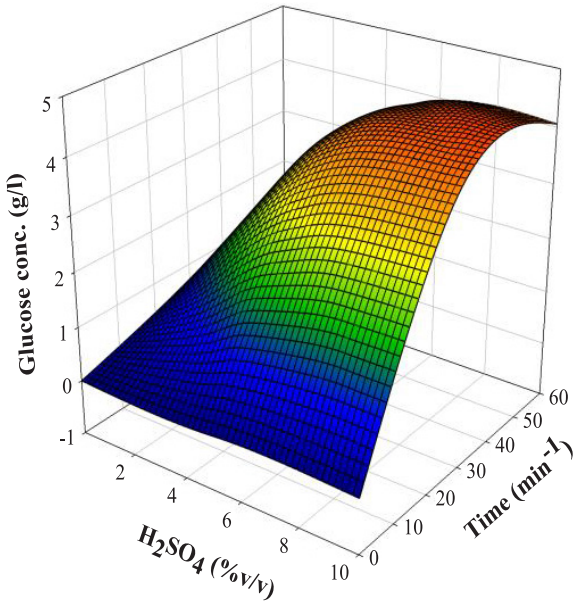

(b)

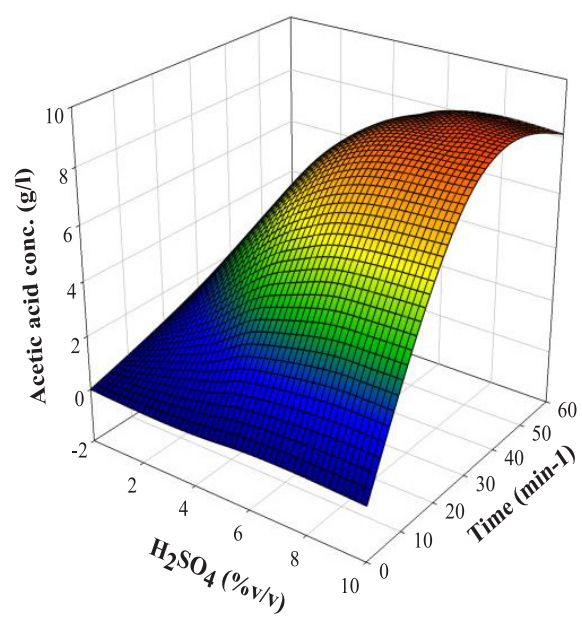

(d)

Figure 5: Effect of sulfuric acid concentration and reaction time on generalized model for prediction of; (a) xylose production, (b) glucose production, (c) furfural formation and (d) acetic acid release.

for acetic acid is given in Table 1. The potential acetic acid concentration $\left(A_{0}\right)$ and kinetic parameter $k_{5}$ were within the range of 1.44-9.18 and 0.0041-0.2213 $\mathrm{min}^{-1}$, respectively. The determinant coefficients $\left(R^{2}=0.97\right.$ 0.99 ) were also well fitted with acetic acid production model. Experimental and predicted data is shown in Figure 3. The value of kinetic parameter $k_{5}$ increased with the increase in acid concentration and reaction temperature. The values of regression parameter for acetic acid production $k_{5}$ obtained were higher than xylose production $k_{l}$ in all experiments (Table 1). These phenomenon shows that the effect of acid on acetyl removal from hemicellulose was higher when compared to that of effect of acid on xylose generation. In another word, xylose production from DPPF could be easily observed from the degradation of acetyl group of hemicellulose. A generalized model for prediction of acetic acid production conducted to correlate $k_{5}$ (equation 20) (Table 2) was also demonstrated in the same direction, which the values of regression parameter $n$ for acetic acid production $k_{5}(n=1.0017)$ obtained were higher than regression parameter $n$ for xylose production $k_{1}(n=0.1660)$. However, the values of regression parameter $n$ for acetic acid production 
$k_{5}(n=0.9187)$ obtained from other researchers were lower than that of regression parameter $n$ for xylose production $k_{1}(n=1.4217)$ [9]. A big difference between this work and others was due to the difference in raw material pretreatment of delignification process. Due to the lignin removal from the surface of PPF, the effect of acid on acetyl groups degradation was increased which may be the reason on higher $k_{5}$ value. The response surface plot of generalized model for acetic acid released in the DPPF hydrolysis (Figure 5d) demonstrated that acetic acid concentration increased with the increase in sulfuric acid concentration and reaction time. This was similar to the previous results of oil palm empty fruit bunch [9] and sorghum straw [18]. Acetic concentration increased from 1-2 $\mathrm{g} \mathrm{L}^{-1}$ with the increase of sulfuric acid concentration from 2 to $6 \%$ at $120^{\circ} \mathrm{C}$ for $30 \mathrm{~min}$. Whereas reaction time increased from 30 to $90 \mathrm{~min}$ at $120^{\circ} \mathrm{C}$ and $6 \%$ sulfuric acid concentration resulting in the increase of acetic acid concentration ( 2 to $3.5 \mathrm{~g} \mathrm{~L}^{-1}$ ) [9]. Therefore, to maximize xylose concentration in the DPPF hydrolysate, the experiments at high sulfuric acid concentration and low reaction time should be conducted for keeping the minimum concentration of acetic acid. In this study, the optimum operating condition for production of xylose from DPPF was 5\% $\left(\mathrm{v} \mathrm{v} \mathrm{v}^{-1}\right)$ sulfuric acid, $120^{\circ} \mathrm{C}$ for $30 \mathrm{~min}$, where all byproducts could be controlled at minimum level.

\section{Conclusions}

As we aim to use DPPF hydrolysate for ethanol production. Maximizing of sugars and minimizing of other products are required. Based on kinetic analysis results, the maximum xylose $\left(30.67 \mathrm{~g} \mathrm{~L}^{-1}\right)$ and glucose $\left(2.2 \mathrm{~g} \mathrm{~L}^{-1}\right)$ concentrations could be obtained by using $5 \%\left(\mathrm{v} \mathrm{v}^{-1}\right)$ sulfuric acid concentration at $120^{\circ} \mathrm{C}$ for $30 \mathrm{~min}$, whereas the concentration of furfural obtained was $0.9 \mathrm{~g} \mathrm{~L}^{-1}$ with the acetic acid concentration of $7.2 \mathrm{gL}^{-1}$.

\section{Acknowledgments}

This research was financially supported by The Joint Graduate School of Energy and Environment (JGSEE), King Mongkut's University of Technology Thonburi, Bangkok, Palm Oil Products and Technology Research Center (POPTEC), Faculty of Agro-Industry and Graduate School, Prince of Songkla University,
Songkhla, Thailand.

\section{References}

[1] S. Prasertsan and P. Prasertsan, "Biomass residues from palm oil mills in Thailand: An overview on quantity and potential usage," Biomass and Bioenergy, vol. 11, pp. 387-395, 1996.

[2] S.C. Chua, C.P. Tan, H. Mirhosseini, O.M. Lai, K. Long, and B.S. Baharin, "Optimization of ultrasound extraction condition of phospholipids from palm-pressed fiber," J. Food Eng., vol. 92, pp. 403-409, 2009.

[3] W. Riansa-ngawong and P. Prasertsan, "Statistical approach for hemicellulose production from delignified palm pressed fiber and used as a bio-material for one-stage production of furfural," Int. J.Biotechnol.Biochem., vol. 7, pp.99-114, 2011.

[4] E. Tamburini, E. Bianchini, A. Bruni, and G. Forlani, "Cosubstrate effect on xylose reductase and xylitol dehydrogenase activity levels, and its consequence on xylitol production by Candida tropicalis," Enzym. Microb. Tech., vol. 46, pp. 352-359, 2010.

[5] J.P. Delgenes, R. Moletta, and J.M. Navarro, "Effects of lignocellulose degradation products on ethanol fermentations of glucose and xylose by Saccharomyces cerevisiae, Zymomonas mobilis, Pichia stipitis, and Candida shehatae," Enzym. Microb. Tech., vol. 19, pp. 220-225, 1996.

[6] E. Palmqvist and B. Hahn-Hägerdal, "Fermentation of lignocellulosic hydrolysates. II: Inhibitors and mechanisms of inhibition," Bioresource Technol., vol. 74, pp. 25-33, 2000.

[7] K. Yan, G. Wu, T. Lafleur, and C. Jarvis, "Production, properties and catalytic hydrogenation of furfural to fuel additives and value-added chemicals," Renew. Sustainable Energy Rev., vol. 38, pp. 663-76, 2014.

[8] M. Gullo, E. Verzelloni, and M. Canonico, "Aerobic submerged fermentation by acetic acid bacteria for vinegar production: Process and biotechnological aspects," Process Biochem., vol. 49, pp. 1571-79, 2014.

[9] S.H.A. Rahman, J.P. Choudhury, and A.L. Ahmad, "Production of xylose from oil palm empty fruit bunch fiber using sulfuric acid," Biochem. Eng. J., vol. 30, pp. 97-103, 2006. 
[10] S.H.A. Rahman, J.P. Choudhury, A.L. Ahmad, and A.H. Kamaruddin, "Optimization studies on acid hydrolysis of oil palm empty fruit bunch fiber for production of xylose," Bioresource Technol., vol. 98, pp. 554-559, 2007.

[11] A. Herrera, S.J. Téllez-Luis, J.A. Ramírez, and M. Vázquez, "Production of xylose from sorghum straw using hydrochloric acid," J. Cereal Sci., vol. 37, pp. 267-74, 2003.

[12] R. Franz, R. Erckel, T. Rienm, R. Woernle, and H.M. Deger, "Lignocellulose saccharification by HF," Appled Science Publishers, London, 1982, pp. 873-878.

[13] A.H. Conner and L.F. Lorenz, "Kinetic modelling of hardwood prehydrolysis. Part III: water and dilute acetic acid of southern red oak prehydrolysis," Wood Fiber Science, vol. 18, pp. 248-263, 1986.

[14] M. Vázquez, M. Oliva, S.J. Téllez-Luis, and J. Ramírez, "Hydrolysis of sorghum straw using phosphoric acid: Evaluation of furfural production," Bioresource Technol., vol. 98, pp. 3053-60, 2007.

[15] A. Rodríguez-Chong, J.A. Ramírez, G. Garrote, and M. Vázquez, "Hydrolysis of sugar cane bagasse using nitric acid: a kinetic assessment," J. Food Eng., vol. 61, pp. 143-152, 2004.

[16] AOAC, "15th ed. Association of Official Analytical Chemists (AOAC)," Official Methods of Analysis of AOAC International, Arlington, VA, USA, 1990.

[17] W. Riansa-ngawong, and P. Prasertsan,
"Optimization of furfural production from hemicellulose extracted from delignified palm pressed fiber using two-stage process," Carbohyd. Res., vol. 346, pp. 103-110, 2011.

[18] S.J. Téllez-Luis, J.A. Ramírez, and M. Vázquez, "Modelling of the hydrolysis of sorghum straw at atmospheric pressure," J. Sci. Food Agr., vol. 82, pp. 505-512, 2002.

[19] R. Yáňez, J.L.Alonso, and J.C. Parajó, "Producton of hemicellulosic sugars and glucose from residual corrugated cardboard," Process Biochem., vol. 39, pp. 1543-1551, 2004.

[20] H.K. Sreenath and T.W. Jeffries, "Production of ethanol from wood hydrolyzate by yeasts," Bioresource Technol., vol. 72, pp. 253-260, 2000.

[21] H.D. Mansilla, J. Baeza, S. Urzúa, G. Maturana, J. Villaseñor, and N. Durán, "Acid-catalysed hydrolysis of rice hull: Evaluation of furfural production," Bioresource Technol., vol. 66, pp. 189-193, 1998.

[22] M. Suwansaard, W. Choorit, J.H. Zeilstra-Ryalls, and P. Prasertsan, "Isolation of anoxygenic photosynthetic bacteria from Songkhla Lake for use in a two-staged biohydrogen production process from palm oil mill effluent," Int. J. Hydrogen Energ., vol. 34, pp. 7523-7529, 2009.

[23] K. Karimi, G. Emtiazi, and M.J. Taherzadeh, "Ethanol production from dilute-acid pretreated rice straw by simultaneous saccharification and fermentation with Mucor indicus, Rhizopus oryzae, and Saccharomyces cerevisiae," Enzym. Microb. Tech., vol. 40, pp. 138-144, 2006. 